\title{
Dietary Nutrient Patterns and Prostate Cancer Risk: A Case-Control Study from Iran
}

\author{
Alireza Bahrami', Mehdi Movahed ${ }^{2}$, Farshad Teymoori', Mohammad Reza \\ Mazandaranian ${ }^{1}$, Bahram Rashidkhani ${ }^{2}$, Azita Hekmatdoost ${ }^{3}$, Ehsan Hejazi ${ }^{3 *}$
}

\begin{abstract}
Background: Prostate cancer is the second common cancer in the world. Although some associations between dietary intakes and prostate cancer have been found, the effects of dietary nutrients interactions have not yet evaluated. The aim of this study is to assess the association between nutrient patterns and risk of prostate cancer. Methods and Materials: Ninety-seven patients with prostate cancer and 205 controls were asked about their demographic and dietary intakes using validated questionnaires. To extract nutrient patterns, Principal Component Analysis (PCA) based on the 35 nutrient items were applied. Varimax rotation was used for improving interpretation and minimizing correlation between the factors. Logistic regression was used to determine the odds ratio (OR) with 95\% confidence interval (CI) of prostate cancer by higher scores on the nutrient patterns. Results: High adherence to the "plant source" pattern was negatively associated with prostate cancer risk (OR 0.29 for the highest vs. the lowest score tertile; $95 \% \mathrm{CI}=0.13-0.65$; $P$ value for trend: $<0.003)$. Similarly, the "antioxidant and fiber" pattern was associated with decreasing risk of prostate cancer (OR 0.06 for the highest vs. the lowest score tertile; $95 \% \mathrm{CI}=0.02-0.19$; P value for trend: $<0.001$ ). There was no significant association for the "mixed" and "vitamin and minerals" pattern with risk of prostate cancer. Conclusion: This study confirms the potential and important role of nutrients on prostate cancer risk. Our finding revealed that "antioxidant and fiber" and "plant source" pattern is inversely associated with prostate cancer risk; however, further longitudinal and trial studies are needed to make a firm conclusion.
\end{abstract}

Keywords: Factor analysis- prostate cancer- nutrient patterns

Asian Pac J Cancer Prev, 20 (5), 1415-1420

\section{Introduction}

Prostate cancer (PC) is the second common cancer in the world (Mwangi and Zhang, 2013). Compared to other countries in Asia the incidence of PC is higher in Iran and it is the third common cancer in men and the six common cancer in Iranian population (Radmard, 2010; Pakzad et al., 2016). Generally the incidence of PC in developing countries is lower than developed countries (Pishgar et al., 2017; Hassanipour et al., 2018), this could be explained by numerous factors such as screening methods, genetic factors, younger age structure, life style and diet (Center et al., 2012; Mottet et al., 2017).

Studies on dietary patterns have reported that high healthy eating index (HEI) or adherence to Mediterranean diet characterized by fruits, grain, vegetable, and nuts are associated with lower risk of prostate cancer (Bosire et al., 2013; Möller et al., 2013; Hashemian et al., 2015; Eslamparast et al., 2017). By contrast, unhealthy dietary patterns like western diet, where red and processed meat and saturated fatty acids are highly consumed, are associated with higher risk of prostate cancer (Askari et al., 2014; Bagheri et al., 2018).

Investigating nutrient interactions through creating nutrient patterns could be proper alternative approach for evaluating the effects of diet on risk of disorder development (Allès et al., 2016). Numerous studies have found the effect of single nutrient on PC risk (Butler et al., 2010; Van Poppel and Tombal, 2011). Since nutrients are consumed in combination, they can be effective in bioavailibity and absorbing of each other ( $\mathrm{Hu}, 2002)$. Therefore, their individual effects cannot be identified.

Until now, there is no study evaluating the association between nutrient patterns and risk of PC in Iranian men. So, the aim of this study is to examine the relationship between nutrient patterns and PC among Iranian men.

${ }^{1}$ Student Research Committee, Department and Faculty of Nutrition Sciences and Food Technology, ${ }^{2}$ National Nutrition and Food Technology Research Institute (WHO Collaborating Center), ${ }^{3}$ Department of Clinical Nutrition and Dietetics, Faculty of Nutrition Sciences and Food Technology, Shahid Beheshti University of Medical Sciences, Tehran, Iran. *For Correspondence: Ehsanhejazi@gmail.com 


\section{Materials and Methods}

\section{Subjects}

This hospital based case-control study carried out in Tehran (the capital of Iran). A hundred forty men with a histological confirmed diagnosis of PC in the preceding six months, who were referred to Shahid Labafi and Modarres hospitals (teaching and referral hospitals), were recruited. One hundred and thirty individuals showed their willingness to participate in the study. The study inclusion criteria were: 1) age between 40 and 80 years; 2) no change in the diet since diagnosis of PC.

According to the adherence of about $73 \%$ of Tehran's adult population of an unhealthy dietary pattern (P2 = 0.53) (Azadbakht et al., 2005) and taking odds ratio $(\mathrm{OR}=2.75)$ (Walker et al., 2005), the ratio of case to control 1 to $2(\mathrm{C}=2), 95 \%$ confidence interval $(\alpha=0.05)$ and $80 \%$ power $(\beta=0.20)$ The sample size was calculated. Using this formula, 79 cases and158 controls were calculated. However, in order to increase the Precision of study, 100 patients in the case group and 200 subjects in the control group were selected.

Based on inclusion criteria, 100 men with PC included in this study (participation rate $=71 \%$ ). Furthermore, 205 patients admitted to the same hospitals (due to ear, nose or eye problems, appendicitis or general surgery) without any special diet were selected as control group. Individuals in case and control groups were matched based on age (with a ten-year interval) and the number of controls was twice as cases.

All participants were interviewed by trained interviewers during their hospital stay to obtain necessary information including history of diabetes, hypertension, smoking status, family history of cancer, life style habits including smoking, marital status and physical activity. The weight of each individual with the least amount of clothing and a sensitivity of 100 grams by digital scale and height without shoes with a sensitivity of $0.1 \mathrm{~cm}$ were measured. The study was approved by ethics committee at Shahid Beheshti University of medical sciences.

Dietary assessment: Usual dietary intake of the cases (1 year before diagnosis) and the controls (1 year before interview) was assessed using a valid and reliable semi-quantitative food frequency questionnaire (FFQ) that consists of 148 food items with standard serving size commonly consumed by Iranian people (Mirmiran et al., 2009). The frequency of consumption of given serving of each food item was questioned on a daily (e.g fruit), weekly (e.g meat) or monthly (e.g fish) basis and converted to daily intakes, assuming one month equal 30 days. The portion sizes were then converted to grams by using the household scales (Ghaffarpour et al., 1999). Consumption of food items in grams were then calculated by multiplying the portion size by daily intake frequency. Daily energy, macronutrients and micronutrients consumption for participants was computed by Nutritionist IV software. Since the Iranian food composition table (FCT) is not complete and comprehensive, analyzes of energy and nutrients were done by using the United States Department of Agriculture (USDA).

\section{Statistical analyses}

Data analysis was performed by Statistical Package Software for Social Science, version 21 (SPSS Inc., Chicago, IL, USA). Normality of the data was checked using histogram chart and Kolmogorov-Smirnov's test. Baseline characteristics of participants were expressed as mean (SD) for quantitative variables, and frequency and percentages for qualitative variables. Comparison of baseline characteristics and dietary intakes between cases and controls were done using independent sample t-test and chi square for continuous and categorical variables respectively.

To extract nutrient patterns, Principal Component Analysis (PCA) based on the 35 nutrient items were applied. Varimax rotation was used for improving interpretation and minimizing correlation between the factors. Statistical correlation between variables and adequacy of sample size was tested, using the Bartlett test of sphericity $(\mathrm{P}<0.001)$ and the Kaiser-Mayer-Olkin test (0.76). The selection of nutrient patterns was done using scree plot (eigenvalue $>2$ ) and factor scores for each nutrient pattern were computed by summing intakes of nutrients weighted by their factor loadings. Each participant received a factor score per identified pattern.

Nutrient patterns were categorized according to tertile of factor scores. Logistic regression was used to determine the odds ratio (OR) with $95 \%$ confidence interval (CI) of prostate cancer by higher scores on the nutrient patterns (above tertile vs below tertile). Tests for linear trend were performed on all ordinal and continuous variables using linear regression analysis producing $\mathrm{p}$-trend values. All models were adjusted for potential confounding variables including: Age, body mass index, marital status (single or married), smoking (yes or no), prostate cancer family history (yes or no), physical activity and dietary energy intake. OR and $95 \%$ confidence interval (CI) were reported, and $\mathrm{P}$-values $<0.05$ were considered as statistically significant.

\section{Results}

After calculating the energy intakes of participants, 3 individuals of case group who's their log scale of total energy intake was either $>3 \mathrm{SD}$ or $<3 \mathrm{SD}$ from the mean were excluded from the study. So, the data of 97 cases and 205 controls were analyzed. The General characteristics and dietary intakes of participants are shown in table 1. Cases were more likely to be smoker, married status and had higher family history of prostate cancer. Controls had higher dietary intakes.

Table 2 shows factor loading matrix for the four retained factors. These factors explained $67.2 \%$ of total variance of nutrient intake. The first pattern characterized by high consumption of manganese, selenium, thiamine, starch, niacin and iron, labeled "vitamin and mineral" pattern. The second Pattern was characterized by high intake of lutein, Vitamin $\mathrm{K}$, total folate, beta-carotene and potassium, named "plant source" pattern. The Third Pattern reflected high intake of insoluble fiber, soluble fiber, Alpha-tocopherol, vitamin E, Beta-cryptoxanthin and vitamin C, called "antioxidant and fiber" pattern, and 
Table1. Baseline Characteristics of Study Participants

\begin{tabular}{|c|c|c|c|}
\hline & Cases $(n=97)$ & Controls $(n=205)$ & P-value* \\
\hline Age $($ mean \pm SD) & $59.82 \pm 9.55$ & $59.59 \pm 9.32$ & 0.85 \\
\hline $\mathrm{BMI}(\mathrm{mean} \pm \mathrm{SD})$ & $25.09 \pm 2.51$ & $25.1 \pm 3.00$ & 0.98 \\
\hline Smoking (yes) n ( \%) & $33(34)$ & $24(11.7)$ & $<0.001$ \\
\hline Prostate cancer family history (yes) $n(\%)$ & $16(16)$ & $13(6.3)$ & $<0.001$ \\
\hline Marital status (married) n (\%) & $95(95)$ & $164(81.6)$ & 0.008 \\
\hline Physical activity $($ mean \pm SD) & $35.55 \pm 6.37$ & $35.79 \pm 5.58$ & 0.52 \\
\hline \multicolumn{4}{|l|}{ Dietary intakes } \\
\hline Energy (mean $\pm \mathrm{SD})$ & $2324.5 \pm 921.8$ & $3178 \pm 1143.7$ & $<0.001$ \\
\hline Carbohydrates (mean \pm SD) & $328 \pm 138$ & $425 \pm 159$ & $<0.001$ \\
\hline Total protein $($ mean $\pm \mathrm{SD})$ & $81 \pm 32.3$ & $100 \pm 33.5$ & $<0.001$ \\
\hline Total fat $($ mean \pm SD) & $83 \pm 47$ & $131.5 \pm 69.5$ & $<0.001$ \\
\hline
\end{tabular}

Data presented as means (standard deviation) or frequencies (percentages); *Independent t-test for quantitative variables and chi-square test for qualitative variables were used. Significance difference, $p$ value $<0.05$

Table 2. Factor Loading Matrix and Explained Variances for the Four Major Nutrient Patterns Identified by Factor Analysis

\begin{tabular}{|c|c|c|c|c|}
\hline \multirow[b]{2}{*}{ Nutrients } & \multicolumn{4}{|c|}{ Nutrient patterns } \\
\hline & 1 & 2 & 3 & 4 \\
\hline Mn (mg) & 0.89 & & & \\
\hline selenium (mg) & 0.89 & & & \\
\hline thiamin (mg) & 0.86 & & & \\
\hline niacin (mg) & 0.8 & & & 0.32 \\
\hline $\mathrm{Fe}(\mathrm{mg})$ & 0.78 & 0.45 & & \\
\hline $\mathrm{Cr}(\mathrm{mg})$ & 0.77 & & & \\
\hline Starch (gr) & 0.76 & & & \\
\hline $\mathrm{Mg}(\mathrm{mg})$ & 0.72 & 0.5 & & \\
\hline $\mathrm{Zn}(\mathrm{mg})$ & 0.71 & 0.44 & & 0.41 \\
\hline $\mathrm{P}(\mathrm{mg})$ & 0.63 & 0.41 & & 0.5 \\
\hline Fiber.Total (gr) & 0.6 & 0.36 & 0.35 & \\
\hline $\mathrm{Cu}(\mathrm{mg})$ & 0.59 & & 0.34 & 0.35 \\
\hline vitB6 (mg) & 0.52 & & 0.44 & 0.5 \\
\hline protein (gr) & 0.51 & 0.31 & & 0.33 \\
\hline lutein (mg) & & 0.93 & & \\
\hline vitK (mg) & & 0.9 & & \\
\hline folate (mg) & 0.35 & 0.81 & & \\
\hline beta_carotene (mg) & & 0.73 & 0.38 & 0.34 \\
\hline $\mathrm{K}(\mathrm{mg})$ & 0.31 & 0.69 & 0.43 & 0.35 \\
\hline \multicolumn{5}{|l|}{ caffeine (mg) } \\
\hline \multicolumn{5}{|l|}{$\mathrm{Na}(\mathrm{mg})$} \\
\hline Fiber.insoluble (gr) & & & 0.74 & \\
\hline fiber.soluble (gr) & & & 0.7 & \\
\hline alpha_toco (mg) & & & 0.69 & \\
\hline vitE (mg) & & & 0.67 & \\
\hline beta_cryptoxantin (mg) & & & 0.62 & \\
\hline $\operatorname{vitC}(\mathrm{mg})$ & & 0.46 & 0.61 & \\
\hline alpha_carotene (mg) & & & 0.51 & 0.39 \\
\hline lycopene (mg) & & & 0.47 & \\
\hline vitB12 (mg) & & & & 0.78 \\
\hline
\end{tabular}

Table 2. Continued

\begin{tabular}{lcccc}
\hline & \multicolumn{4}{c}{ Nutrient patterns } \\
Nutrients & 1 & 2 & 3 & 4 \\
\hline riboflavin. (mg) & 0.47 & & & 0.72 \\
vitA.REA (mg) & & 0.42 & 0.32 & 0.67 \\
pantothenic (mg) & 0.5 & 0.45 & & 0.58 \\
Ca (mg) & 0.33 & 0.49 & & 0.54 \\
vitD (micro.gr) & & & & 0.5 \\
Explained variance (\%) & 42.2 & 11.9 & 7.1 & 5.9 \\
Cumulative explained & 42.2 & 54.2 & 61.3 & 67.2 \\
variance (\%) & & & &
\end{tabular}

Estimated by a Principle Component Analysis (PCA) performed on 35 nutrients. Nutrients with loadings $>0.60$ were shown in bold and loadings less than 0.3 (in absolute value) are suppressed.

The forth pattern had the greatest loading on vitamin B12, riboflavin and vitamin A named "mixed" pattern.

Table 3 presents the odds ratio (OR) and corresponding confidence interval $(\mathrm{CI})$ for prostate cancer according to tertile of factor scores for the retained nutrients pattern. After adjusting the effects of potential confounders, there was no significant association between "vitamin and mineral" pattern and prostate cancer. High adherence to the "plant source" pattern was negatively associated with prostate cancer risk (OR 0.29 for the highest vs. the lowest score tertile; $95 \% \mathrm{CI}=0.13-0.65$; $\mathrm{P}$ value for trend: $<0.003)$. Similarly, the "antioxidant and fiber" pattern was associated with decreasing risk of prostate cancer (OR 0.06 for the highest vs. the lowest score tertile; $95 \% \mathrm{CI}=0.02-0.19 ; \mathrm{P}$ value for trend: $<0.001$ ). There was no significant association for the "mixed" pattern with risk of prostate cancer.

\section{Discussion}

In this study, four nutrient patterns were identified. The "antioxidant and fiber" and "plant source" patterns were inversely associated with prostate cancer whereas no significant association were found with "vitamin and mineral" and "mixed" patterns. The "antioxidant 
Table 3. Odds Ratios (OR) of Prostate Cancer and 95\% Confidence Intervals (CI) According to Tertile Scores on The Nutrient Patterns

\begin{tabular}{|c|c|c|c|c|c|c|c|}
\hline Nutrient pattern & Cases/Controls & $\mathrm{OR}^{\mathrm{a}}$ & $95 \% \mathrm{CI}$ & $\mathrm{P}$ for trend* & $\mathrm{OR}^{\mathrm{b}}$ & $95 \% \mathrm{CI}$ & P for trend* \\
\hline First pattern & & & & $<0.001$ & & & 0.72 \\
\hline $\mathrm{T} 1$ & $51 / 50$ & 1 & reference & & 1 & reference & \\
\hline $\mathrm{T} 2$ & $26 / 76$ & 0.33 & $0.18-0.60$ & & 0.55 & $0.26-1.17$ & \\
\hline $\mathrm{T} 3$ & $23 / 79$ & 0.27 & $0.14-0.50$ & & 0.91 & $0.36-2.24$ & \\
\hline Second pattern & & & & 0.001 & & & 0.003 \\
\hline $\mathrm{T} 1$ & $41 / 60$ & 1 & reference & & 1 & reference & \\
\hline $\mathrm{T} 2$ & $40 / 62$ & 0.92 & $0.52-1.62$ & & 0.61 & $0.30-1.25$ & \\
\hline $\mathrm{T} 3$ & $19 / 83$ & 0.32 & $0.17-0.61$ & & 0.29 & $0.13-0.65$ & \\
\hline Third pattern & & & & $<0.001$ & & & $<0.001$ \\
\hline $\mathrm{T} 1$ & $65 / 36$ & 1 & reference & & 1 & reference & \\
\hline $\mathrm{T} 2$ & $25 / 77$ & 0.17 & $0.09-0.32$ & & 0.16 & $0.07-0.34$ & \\
\hline $\mathrm{T} 3$ & Oct-92 & 0.05 & $0.02-0.12$ & & 0.06 & $0.02-0.19$ & \\
\hline Fourth pattern & & & & 0.24 & & & 0.86 \\
\hline $\mathrm{T} 1$ & $31 / 70$ & 1 & reference & & 1 & reference & \\
\hline $\mathrm{T} 2$ & $42 / 60$ & 1.56 & $0.87-2.79$ & & 1.06 & $0.52-2.16$ & \\
\hline $\mathrm{T} 3$ & $27 / 75$ & 0.81 & $0.44-1.49$ & & 0.93 & $0.43-1.98$ & \\
\hline
\end{tabular}

* Significant trend (Linear regression analysis, p-trend value $<0.05$ ); Logistic regression was performed to obtain the odds ratio (95\% CI) of prostate cancer; ${ }^{\text {a }}$, Age adjusted model; ${ }^{\mathrm{b}}$, Adjusted additionally for prostate cancer family history (yes, no), body mass index, smoking (yes or no), marital status (single or married), dietary energy intake and physical activity.

and fiber" pattern was greatest loaded on vit $\mathrm{E}$, vit $\mathrm{C}$, Beta-cryptoxantin, Alpha-tocopherol, soluble fiber and insoluble fiber. Previous studies demonstrated that the increased level of oxidative stress (OS) causing prostate cancer, so micronutrient antioxidant could be effective in neutralizing the harmful effect of OS by involving in reactive oxygen species(ROS) elimination (Udensi and Tchounwou, 2016). The present finding seem to be consistent with other researches which found higher intake of dietary and supplementary vit $E$ are inversely associated with risk of prostate cancer (Wright et al., 2007; Bidoli et al., 2009). However, some studies found no association or increased risk of prostate cancer with vitamin E (Gaziano et al., 2009; Klein et al., 2011). This discrepancy in results may be due to differences in baseline levels of OS. Kirsh et al., (2006) revealed that risk of prostate cancer decreased by increasing dose and duration of vitamin $\mathrm{E}$ supplementation in current and recent smokers. In line with our results, a meta-analysis reported dietary vitamin $\mathrm{C}$ intake associated with reduced prostate cancer risk (Bai et al., 2015), while cohort and trial studies have found no association (Schuurman et al., 2002; Bidoli et al., 2009; Gaziano et al., 2009). It has been supposed that dietary fiber might decrease risk of prostate cancer by improving insulin sensitivity and decrease bioactivity of Insulin-like growth factor-1 IGF-1 (Barnard et al., 2002). Previous cohort and case-control studies have demonstrated that total, insoluble, soluble and legume fiber are inversely associated with prostate cancer risk (Tabung et al., 2012; Deschasaux et al., 2014; Sawada et al., 2014). Similarly, the "plant source" pattern (loaded heavily on potassium, Vitamin K, total folate, beta-carotene and lutein) was negatively associated with risk of prostate cancer. Numerous studies have shown the protective effects of vitamin $\mathrm{K}$ and carotenoids consumption on prostate cancer risk (Nimptsch et al., 2008; Nimptsch et al., 2015; Dasari et al., 2017), However there is conflicting evidence regarding folate intake and prostate cancer risk. Some Studies found no association between dietary and total folate intake and prostate cancer risk, while other studies reported that higher blood folate levels increased prostate cancer risk (Figueiredo et al., 2009; Wang et al., 2014). It is possible that synergistic effect of other nutrients in this pattern, cause the significant effect of folate on reducing the risk of prostate cancer, that is completely in line with our hypothesis based on the effect of interactions between nutrients and the predominance of the effect of a higher consumption of nutrients that exhibit behavioural coexistence.

Inverse association between green leafy and cruciferous vegetables (the main source of vitamin K1) and prostate cancer risk have been reported in several studies (Hardin et al., 2011; Dasari et al., 2017). Also, the protective effect of vitamin K2 (another form of vitamin $\mathrm{K}$ that found in animal product) reported in one cohort study (Nimptsch et al., 2008). Anticancer effects of vitamin $\mathrm{K}$ can be explained by several mechanisms including decreasing ROS production or increase in ROS elimination by active scavenging systems, activating apoptosis pathways and inducing apoptosis by active Caspase dependent apoptosis via the MAP kinase pathway (Showalter et al., 2010; Dasari et al., 2018), inducing autophagy that can regulate living cells to remove damaged or long-lived cytosolic protein (Yokoyama et al., 2008) .

Several studies have reported a negative association between intake of carotenoids and risk of PC (Antwi et al., 2016; Van Hoang et al., 2018). Epidemiological studies demonstrated that consumption of fruits and vegetables rich in lutein are inversely related to incidence of prostate cancer (McCann et al., 2005; Zhang et al., 2007). The 
anticancer effects of lutein could be due to the function of lutein as an antioxidant, a chemo preventative agent or a regulator of apoptosis, angiogenesis and gap junctional intercellular communication (Ribaya-Mercado and Blumberg, 2004).

This study has some limitations. Case-control studies limitations could affect the result and should be taken into consideration. The probability of selection bias in case-control studies cannot be avoided. Furthermore, possible nutritional problems of control subjects might dilute the association of dietary intakes and prostate cancer risk. In this regard, hospital controls (oppose to community controls) were recruited because of higher cooperation and participation rate. To avoid selection bias, and reduce the possibility of recall bias, patients with less than 6 month of diagnosis were enrolled in the recent study.

In conclusion, this study confirms the potential and important role of nutrients on prostate cancer risk. Our finding revealed that "antioxidant and fiber" and "plant source" pattern is inversely associated with prostate cancer risk; however, further longitudinal and trial studies are needed to make a firm conclusion.

\section{Acknowledgments}

This study is related to the project NO. 1396/114499 From Student Research Committee, Shahid Beheshti University of Medical Sciences, Tehran, Iran. We also appreciate the "Student Research Committee" and "Research \& Technology Chancellor" in Shahid Beheshti University of Medical Sciences for their financial support of this study.

\section{References}

Allès B, Samieri C, Lorrain S, et al (2016). Nutrient patterns and their food sources in older persons from France and Quebec: dietary and lifestyle characteristics. Nutrients, 8, 225.

Antwi SO, Steck SE, Su LJ, et al (2016). Carotenoid intake and adipose tissue carotenoid levels in relation to prostate cancer aggressiveness among African-American and EuropeanAmerican men in the North Carolina-Louisiana prostate cancer project (PCaP). Prostate, 76, 1053-66.

Askari F, Parizi MK, Jessri M, et al (2014). Dietary patterns in relation to prostate cancer in Iranian men: a case-control study. Asian Pac J Cancer Prev, 15, 2159-63.

Azadbakht L, Mirmiran P, Hosseini F, et al (2005). Diet quality status of most Tehranian adults needs improvement. Asia Pac J Clin Nutr, 14, 163-8.

Bagheri A, Nachvak SM, Rezaei M, et al (2018). Dietary patterns and risk of prostate cancer: a factor analysis study in a sample of Iranian men. Health Promot Perspect, 8, 133-8.

Bai X-Y, Qu X, Jiang X, et al (2015). Association between dietary vitamin c intake and risk of prostate cancer: a meta-analysis involving 103,658 subjects. J Cancer, 6, 913-21.

Barnard R, Aronson W, Tymchuk C, et al (2002). Prostate cancer: another aspect of the insulin-resistance syndrome? Obes Rev, 3, 303-8.

Bidoli E, Talamini R, Zucchetto A, et al (2009). Dietary vitamins $\mathrm{E}$ and $\mathrm{C}$ and prostate cancer risk. Acta Oncol, 48, 890-4.

Bosire C, Stampfer MJ, Subar AF, et al (2013). Index-based dietary patterns and the risk of prostate cancer in the NIH-AARP diet and health study. Am J Epidemiol, 177, 504-13.
Butler LM, Wong AS, Koh W-P, et al (2010). Calcium intake increases risk of prostate cancer among Singapore Chinese. Cancer Res, 70, 4941-8.

Center MM, Jemal A, Lortet-Tieulent J, et al (2012). International variation in prostate cancer incidence and mortality rates. Eur Urol, 61, 1079-92.

Dasari S, Ali SM, Zheng G, et al (2017). Vitamin K and its analogs: Potential avenues for prostate cancer management. Oncotarget, 8, 57782-99.

Dasari S, Samy ALPA, Kajdacsy-Balla A, et al (2018). Vitamin $\mathrm{K} 2$, a menaquinone present in dairy products targets castration-resistant prostate cancer cell-line by activating apoptosis signaling. Food Chem Toxicol, 115, 218-27.

Deschasaux M, Pouchieu C, His M, et al (2014). Dietary total and insoluble fiber intakes are inversely associated with prostate cancer risk-3. J Nutr, 144, 504-10.

Eslamparast T, Sharafkhah M, Poustchi H, et al (2017). Nut consumption and total and cause-specific mortality: results from the Golestan Cohort Study. Int J Epidemiol, 46, 75-85.

Figueiredo JC, Grau MV, Haile RW, et al (2009). Folic acid and risk of prostate cancer: results from a randomized clinical trial. J Natl Cancer Inst, 101, 432-5.

Gaziano JM, Glynn RJ, Christen WG, et al (2009). Vitamins E and $\mathrm{C}$ in the prevention of prostate and total cancer in men: the Physicians' Health Study II randomized controlled trial. JAMA, 301, 52-62.

Ghaffarpour M, Houshiar-Rad A, Kianfar H (1999). The manual for household measures, cooking yields factors and edible portion of foods. Tehran Nashre Olume Keshavarzy, 7, 213.

Hardin J, Cheng I, Witte JS (2011). Impact of consumption of vegetable, fruit, grain, and high glycemic index foods on aggressive prostate cancer risk. Nutr Cancer, 63, 860-72.

Hashemian M, Poustchi H, Abnet CC, et al (2015). Dietary intake of minerals and risk of esophageal squamous cell carcinoma: results from the Golestan Cohort Study. Am J Clin Nutr, 102, 102-8.

Hassanipour S, Fathalipour M, Salehiniya H (2018). The incidence of prostate cancer in Iran: a systematic review and meta-analysis. Prostate Int, 6, 41-5.

Hu FB (2002). Dietary pattern analysis: a new direction in nutritional epidemiology. Curr Opin Lipidol, 13, 3-9.

Kirsh VA, Hayes RB, Mayne ST, et al (2006). Supplemental and dietary vitamin $\mathrm{E}, \beta$-carotene, and vitamin $\mathrm{C}$ intakes and prostate cancer risk. $J$ Natl Cancer Inst, 98, 245-54.

Klein EA, Thompson IM, Tangen CM, et al (2011). Vitamin E and the risk of prostate cancer: the Selenium and Vitamin E Cancer Prevention Trial (SELECT). JAMA, 306, 1549-56.

McCann SE, Ambrosone CB, Moysich KB, et al (2005). Intakes of selected nutrients, foods, and phytochemicals and prostate cancer risk in western New York. Nutr Cancer, 53, 33-41.

Mirmiran P, Esfahani FH, Mehrabi Y, et al (2010). Reliability and relative validity of an FFQ for nutrients in the Tehran lipid and glucose study. Public Health Nutr, 13, 654-62.

Möller E, Galeone C, Andersson TM-L, et al (2013). Mediterranean Diet Score and prostate cancer risk in a Swedish population-based case-control study. J Nutr Sci, 2.

Mottet N, Bellmunt J, Bolla M, et al (2017). EAU-ESTRO-SIOG guidelines on prostate cancer. Part 1: screening, diagnosis, and local treatment with curative intent. Eur Urol, 71, 618-29.

Mwangi W, Zhang J (2013). Dietary factors and risk of advanced prostate cancer. Eur J Cancer Prev, 23, 96-109.

Nimptsch K, Rohrmann S, Linseisen J (2008). Dietary intake of vitamin $\mathrm{K}$ and risk of prostate cancer in the Heidelberg cohort of the European Prospective Investigation into Cancer and Nutrition (EPIC-Heidelberg). Am J Clin Nutr, 87, 985-92.

Nimptsch K, Wu K, Pischon T, et al (2015). Dietary intake of 
vitamin $\mathrm{K}$ and risk of prostate cancer in a cohort of Us health professionals. Ann Nutr Metab, 67, 392.

Pakzad R, Rafiemanesh H, Ghoncheh M, et al (2016). Prostate cancer in Iran: trends in incidence and morphological and epidemiological characteristics. Asian Pac J Cancer Prev, 17, 839-43.

Pishgar F, Ebrahimi H, Moghaddam SS, et al (2017). Global, regional and national burden of prostate cancer, 1990-2015: results from the global burden of disease study 2015. J Urol, 199, 1224-32.

Radmard AR (2010). Five common cancers in Iran. Arch Iran Med, 13, 143-6.

Ribaya-Mercado JD, Blumberg JB (2004). Lutein and zeaxanthin and their potential roles in disease prevention. $J$ Am Coll Nutr, 23, 567-87.

Sawada N, Iwasaki M, Yamaji T, et al (2014). Fiber intake and risk of subsequent prostate cancer in Japanese men. Am J Clin Nutr, 101, 118-25.

Schuurman AG, Goldbohm RA, Brants HA, et al (2002). A prospective cohort study on intake of retinol, vitamins $\mathrm{C}$ and E, and carotenoids and prostate cancer risk (Netherlands). Cancer Causes Control, 13, 573-82.

Showalter SL, Wang Z, Costantino CL, et al (2010). Naturally occurring $\mathrm{K}$ vitamins inhibit pancreatic cancer cell survival through a caspase-dependent pathway. J Gastroenterol Hepatol, 25, 738-44.

Tabung F, Steck SE, Su LJ, et al (2012). Intake of grains and dietary fiber and prostate cancer aggressiveness by race. Prostate Cancer, 2012.

Udensi UK, Tchounwou PB (2016). Oxidative stress in prostate hyperplasia and carcinogenesis. J Exp Clin Cancer Res, 35, 139.

Van Hoang D, Pham NM, Lee AH, et al (2018). Dietary carotenoid intakes and prostate cancer risk: A case-control study from Vietnam. Nutrients, 10, 70.

Van Poppel H, Tombal B (2011). Chemoprevention of prostate cancer with nutrients and supplements. Cancer Manag Res, 3, 91-100.

Walker M, Aronson KJ, King W, et al (2005). Dietary patterns and risk of prostate cancer in Ontario, Canada. Int J Cancer, 116, 592-8.

Wang R, Zheng Y, Huang J-Y, et al (2014). Folate intake, serum folate levels, and prostate cancer risk: a meta-analysis of prospective studies. BMC Public Health, 14, 1326.

Wright ME, Weinstein SJ, Lawson KA, et al (2007). Supplemental and dietary vitamin $\mathrm{E}$ intakes and risk of prostate cancer in a large prospective study. Cancer Epidemiol Biomarkers Prev, 16, 1128-35.

Yokoyama T, Miyazawa K, Naito M, et al (2008). Vitamin K2 induces autophagy and apoptosis simultaneously in leukemia cells. Autophagy, 4, 629-40.

Zhang J, Dhakal I, Stone A, et al (2007). Plasma carotenoids and prostate cancer: a population-based case-control study in Arkansas. Nutr Cancer, 59, 46-53.

This work is licensed under a Creative Commons AttributionNon Commercial 4.0 International License. 